Guest Editorial

\section{Notes toward a Restoration Ethic}

\author{
By Jamie Sayen \\ "This is the irony of our age: 'hands-on' management \\ is needed to restore 'hands-off' wilderness character." \\ -Reed Noss.
}

\section{I}

Since there is nowhere enough wilderness to permit the full mystery of evolution to flourish, we, as a culture, must begin the daunting task of restoring vast tracts of damaged lands to a condition where they can begin to re-wild themselves. We must also restore other lands so that healthy human cultures can be restored to their rightful role in the process of natural succession.

But, to speak of the ecological restoration by humans of ecosystems and species damaged or destroyed by humans is to speak in paradoxes. Enter at your own risk. Bring a healthy dose of humility and recognize that you are attempting work that only Mother Earth can properly do.

Do not be deterred by the apparent absurdity of the task. The alternatives are a surrender to despair and the collapse of the biosphere.

In other words, the only option left to us is to begin to live by an ethic which: (1) Preserves all existing wildland fragments; (2) Opposes all on-going abuses to the biosphere, whether on a global or local level; (3) Restores, in an ecologically responsible fashion, large tracts of lands that have suffered from human destruction and development; (4) Restores human culture to natural succession; and (5) Takes an aggressive public advocacy stance on the above and related issues.

\section{II}

Preservation and restoration are inseparable. The values that are at the heart of the preservation movementthe intrinsic value of wildness and the impulse to halt the catastrophic loss of biodiversity and genetic diversityare at the heart of an ecologically responsible restoration movement.

Preservation is the preventive medicine of the restoration movement. If it ain't broke, you don't need to fix it. But, in the case of critically endangered species or ecosystems, preservation is not enough. Active restorative efforts are necessary. In the eastern United States, for example, no large, sustainable ecosystems remain intact.

Mr. Sayen is a coordinator of Preserve Appalachian Wilderness (PAW), a grassroots environmental group whose long-range vision is to restore vast tracts of wilderness in the eastern United States.

His address is PAW, RFD 1, Box 530, N. Stratford, NH 03590, 603-6362952.
We must preserve the few undeveloped tracts (See The Big Outside, by Dave Foreman and Howie Wolke, Ned Ludd Books, P.O. Box 5141, Tucson, AZ, 1989, for an inventory of the last remaining large roadless areas in the lower 48 states), and we must begin to restore surrounding areas that have been developed and/or degraded so that, ultimately, there will be large, viable tracts of wilderness. In a comprehensive strategy, preservation and restoration are inextricable.

This issue was debated at some length in a special discussion session attended by perhaps 60 participants at the conclusion of the SER Conference in Oakland last January. There was some reluctance to enter into the political arena, and some felt that the Society should not duplicate the efforts of other environmental groups that focus on preservation work.

Several times individuals referred to restoration work as "healing" work, drawing the analogy that restorationists are ecological MDs. Proponents of a strong position on the preservation of all remaining wildlands pointed out that the very need for restoration implies that too much has already been destroyed, and, therefore, it is imperative to save all remaining wildlands. SER doesn't have to replace the Sierra Club or Earth First!, but it must go on record in favor of this preventive medicine. If a doctor were trying to operate, we asked, would she want someone still pummelling the patient?

As the discussion developed, more and more people spoke in favor of preservation.. At length, Bill Jordan III, the editor of Restoration and Management Notes, said that to him, "Restoration implies preservation." We agreed, but stressed the likelihood that this implication will be lost on non-members unless this position is explicitly spelled out.

\section{III}

The issue of mitigation was also debated at some length. During the conference, several speakers had asked questions like: Is mitigation a complement to or a substitute for the preservation of biodiversity? and, Do created wetlands replace the ecological functions of naturally-occurring wetlands? Speaker after speaker answered these questions with a resounding "No." We can put back some of the pieces, but there is always a loss of biodiversity. Always. This prompted Dr. Joy Zedler (San Diego) to say that we cannot allow the destruction of any more natural wetlands. I would extend that protection to any natural system.

Although no one was happy with mitigation, it was pointed out that most of the money available is for mitigation rather than "pure" restoration work. Someone said he felt it is important for the Society to find ways of making restoration work pay so that restorationists are not forced to do mitigation work.

Gradually, a group consensus against mitigation emerged. One person brought down the house when he called mitigationists "Biostitutes." An employee of the Forest Service, an agency which, he said, had lost its respectability 45 years ago, said: “Don't allow yourselves 
to be used, or you'll become an apologist for development." Another person pointed out that mitigation is allowing the destruction of rare and endangered species, communities and ecosystems.

At the end of the meeting on the future directions of the Society, someone urged those assembled not to confuse ends with means. The goal of the Society, he said, is ecological health. The means to achieve this are restoration, preservation, and management. Mitigation, by subverting the healing goal, clearly is not an appropriate tool.

\section{IV}

Keynote speaker Chris Maser said, "There is no such thing as reforestation. Who can plant a forest?" He also said: "We can't fix nature. We can put back pieces and allow nature to heal herself."

The discussion of appropriate restoration goals, strategies, and techniques leads directly into the realm of paradox. O. H. Frankel and M. E. Soule, in Evolution and Conservation (p. 126), speak of "our abysmal ignorance of biological processes in complex ecosystems." With humility, patience, and attentiveness, we can gain valuable insights into that complex mystery, but our ignorance, not our omniscience, remains the dominant factor in our efforts "to save the world" by "playing gods" who are trying to put back some of the pieces.

We must devise restoration goals, strategies and techniques which are realistic, given this inescapable ignorance. Any other approach would be arrogant and futile. We must be clear about what can and can't be done.

Efforts to re-create or replicate damaged ecosystems can never fully succeed. Even if we knew all the parts (down to site- specific soil microbes and mycorrhizal fungi), we couldn't begin to understand - or even fully suspect - the basic structure of the area to be restored, let alone the network of relations and functions within that system.

The goal of restoration, therefore, must be natural recovery. Remove the destructive forces. Attempt to restore, in an ecologically appropriate manner, as many species, communities, functions and structures as possible, taking a holistic view of the ecosystem. Proceed in accordance with natural succession. Vigilantly monitor and guard against further human abuses and let nature run her course. The objective - in my view-is to restore natural processes and something of the spirit of the place, not some static, idealized, pre-settlement picture.

\section{V}

What is the relationship of the restorer to the restoration project? Are we outside the ecosystem, tinkering to repair it for further human use (and abuse)? Or are we working to restore human culture as an integral part of the restored ecosystem so that human culture again lives within the limits of the carrying capacity of its local watershed or ecosystem? I subscribe wholeheartedly to the latter approach.

At the conference, Stephanie Kaza (Muir Beach, CA) suggested that there are two challenges facing res- torationists: repair work and the need to establish a new way of relating to the planet. Otherwise, she said, restoration work is merely "emergency triage."

The finest example I know of efforts to restore human culture while restoring damaged ecosystems is the work of the Mattole (California) Restoration Council (MRC). The highlight of the conference, for me, was the presentation by the grassroots restorationists of the MRC who believe that a restoration ethic should be connected with lifestyles (that is, restore the human culture of the watershed at the same time the watershed is being restored so that the two restoration projects merge into one). "The most valuable thing we are doing," says Freeman House of the MRC, "is influencing a shift in cultural attitudes."

To this dirty fingernail crowd, restoration work is a job which must be done, not a professional career; it is a labor of love. The residents of the Mattole have found that jobs like surveying and moving boulders help build a strong community understanding of the local landscape. School children are involved in restoration projects from an early age.

The representative of the MRC welcome experts as advisors, and they are quick to express their gratitude for expert assistance they have received. They believe, however, that the work should be community based and community run. They feel restoration needs to become a significant part of the local economy. The ideal worker is a local worker. "I can't think of anything better," says House, "than to be paid to walk up and down a stream near your house."

I would urge young restorationists to adopt a watershed and tailor their research to serve the practical needs of that watershed. Every watershed in the world has a niche for a council of this kind.

In an essay titled "Future Primitive" (PLANET/DRUM\#3, North Pacific Alive, Planet Drum Foundation, P. O. Box 31251, San Francisco, CA 94131), House once wrote, "We will be informed by earthworms and plankton. We will study that authority which resides in place and act out our lives accordingly."

\section{VI}

Recently Daniel Janzen (SER Board member at-large, Philadelphia), frustrated by the narrow focus of most biological research, told the National Science Foundation: "The most intellectually challenging issue in conservation biology is how to get the academic community to stop intellectualizing conservation biology to death and get out there and actually do something about it." He advocated a "warlike mentality."

Restorationists are already out in the field doing something, but much more must be done both in the field and in the realm of public advocacy. One participant at the SER conference said: "If we are going to save the Earth, we must be advocates."

I believe that SER must loudly oppose the continuing biological destruction of North America and the entire world. Otherwise, no matter how well-intentioned our efforts may be, we will be kidding ourselves. In the next 
two decades we could lose the ability to recover 4,000 species in the wild in North America. Many of these species might survive in captive situations, but they would be gone from the wild. Over 1,000 species are critically endangered right now.

As restorationists, we must clearly prioritize our objectives. We must focus on preserving, protecting and restoring the most important biologically sensitive lands and waters in North America and throughout the planet.

We need an Endangered Ecosystem Act, a Biodiversity Act, and a National Biological Preserve System. (I would suggest that this system could begin with the lands now mis-managed by the US Forest Service, an ecologicallybackward bureaucracy which ought to be abolished.)

As restorationists, whether professional or grassroots, we must immediately address the political, economic and social factors causing the destruction of biological diversity. Silence, even while doing restoration work, is complicity.

\section{VII}

Finally, we must be guided by an ethic of humility which acknowledges "our abysmal ignorance." Can-do optimism is a sure prescription for playing god and furthering the destruction caused by what conservation biologist David Ehrenfeld has aptly called "the arrogance of humanism."

Instead of attempting to adjust, control, or manage, we should be working to restore the possibility of the evolutionary dance. The irony of this ethic is that to achieve this long-term goal, we sometimes have to engage in short-term manipulations. A healthy dose of humility is essential for such a delicate task.

As restorationists, we should be working to create a society in which restoration work is no longer necessary. Paradoxically, our ultimate goal should be to put ourselves out of business.

R\&MN Guest Editorials provide space for the expression of diverse views on all matters related to ecological restoration. Readers interested in presenting viewpoints, replying to previous editorials or articles, or otherwise contributing to this ongoing discussion are encouraged to submit letters or to contact the editor to suggest topics for discussion. 